\title{
Comparative Evaluation of Phytochemical Constituents and Antioxidant Capacity of Some Ethnomedicinal Plants Used In Western Nigeria
}

\author{
Faeji, C.O ${ }^{1}$, Oladunmoye, M.K ${ }^{2}$ \\ Department of Medical Microbiology and Parasitology, CHMS, Afe Babalola University, Ado Ekiti ${ }^{l}$ \\ Department of Microbiology, Federal University of Technology, Akure, Ondo State ${ }^{2}$
}

\begin{abstract}
This study investigated and compared the phytochemical constituents and antioxidant property of Phyllanthus amarus, Vernonia amygdalina, Carica papaya and Jatropha curcus which are commonly used in traditional medicine. This was achieved by evaluating the quantitative and qualitative presence of the phytochemicals and also determining the free radical scavenging potentials of the plant leaf extracts. The results of this study revealed that the leaf extracts of the test plants contain some proportions of important phytochemicals which includes alkaloids, tannins, saponins, flavonoids, phenols, steroids, glycosides, cardiac glycoside. In furtherance, it showed that the selected plants vary significantly in their percentage ferric reducing antioxidant potentials (FRAP) expressed in gallic acid equivalents(GAE) ranging from $63.624 \pm 0.14$ to $165.076 \pm 0.24 \mathrm{mg} / 100 \mathrm{~g}$ and all the sample extracts exhibited moderate to significant inhibition of 1,1 diphenyl-2-picryl-hydrazyl (DPPH) activity expressed in trolox equivalent (TAEC) ranging from $1.306 \pm 0.20$ to $38.943 \pm 0.11 / 100 g$. Considering all the parameters assayed, antioxidants capacities were significant in the sequence of P.amarus, V. amygdalina, J. curcas and C. Papaya. This current study shows that the test plants contain useful phytochemicals which makes them employable in traditional medical practices. However more work needs to be done to determine which of these phyto-constituents exert the greatest potency in therapeutic and antioxidant activities.
\end{abstract}

Keywords: Phytochemicals, Antioxidant, Assessment, Phyllanthus amarus, Vernonia amygdalina, Carica papaya Jatropha curcus, Medicinal plants.

\section{Introduction}

Plant usage in the therapeutic management of diseases started with life and goes as far back as several centuries. In recent years, with technology and research, it has been proven that many plants do indeed have medicinal values (Adeyemi et al., 2002). There are several of these plants and some of these plants used for medicinal purposes in Nigeria include Phyllanthus sp, Garcina kola, Vernonia amygdalina, Jatropha curcas, Carica papaya, Ocimum basilicum and Cola nitida amongst others and these plants are widely distributed in the eastern and western parts of Nigeria.

In Africa and most Asian countries, the use of folk medicine is rampant and the patronage for herbal cure is a regular practice (Akpanabiatu et al., 2005). These herbs claim to provide health care to majority of the people as a cure and also as preventive approach in the developing countries for common sicknesses (Gabriel et al., 2007).

Many plants have phytochemicals and also possess antioxidant activity which may reduce the risk of infection, cancer and diseases, for example, alkyl sulfide (found in onions and garlic), carotenoids (from carrots), and flavonoids (present in fruits and vegetables) (Akpanabiatu et al., 2005). Also Reactive oxygen-free radicals (ROS) have been implicated in many of these diseases and cancer, these free radicals, which cause tissue damage via oxidative stress, are generated by aerobic respiration, inflammation, and lipid peroxidation. The antioxidant capacities exploited in plants, however, help alleviate or prevent harmful effects of this ROS (Anderson et al., 2001).

The beneficial extracts from these plants are obtained through extraction and the efficacy of a medicinal plant or extract may depend on the mode of preparation/extraction of the plant material and as well the solvent for this extraction for consumption and/or remedy for various diseases. Many are soaked, some are chewed, cooked, roasted or applied on the body surface, while some have to go through a thorough process of extraction with chemical solvents before use. All the various methods of use are to enhance the bioavailability and proper extraction of active phyto-constituents leading to the efficacy of the plant material. However, if the method of preparation and intake of the plant material is wrong, the desired result may not be achieved.

Phytochemicals present in plants are important as they may determine the medicinal value posed by the plants. These phytochemicals are categorized into two main sets namely primary and secondary. The primary 
consists of amino acids, proteins, sugars and the secondary comprises the alkaloids, flavonoids, tannins, terpenoids, saponin and others. Majority of the phytochemicals have been known to exert valuable therapeutic and pharmacological effects such as insecticidal, bactericidal, fungicidal, anti-parasitic, anti-constipative and probable antiviral effects (Oladunmoye, 2012).

Therefore this present study investigates and compares the secondary phytochemical constituents and antioxidant property of Phyllanthus amarus, Vernonia amygdalina, Carica papaya and Jatropha curcus locally used in traditional medicine.

\section{Materials And Methods}

\section{Collection and Identification of Plants}

The leaves of the study plants including Phyllanthus amarus, Vermonia amygdalina, Carica papaya and Jatropha curcus were collected from its natural habitats between the months on April and June, 2016. The plants were authenticated at the Department of Biological Sciences, Afe Babalola University, Ado Ekiti using standard keys and descriptions.

\section{Plant Preparation and Extraction}

The collected plants were air dried under shade and ground into powder. 500g of the powder was extracted with $2000 \mathrm{ml}$ of solvents(Suresh et al, 2011). The solvents include Water, Ethanol, Methanol and Hexane. Using a digital weighing balance, $500 \mathrm{~g}$ of each powder was weighed and differently soaked in $2000 \mathrm{ml}$ of solvent at a ratio of 1:4 (powder/solvent). The mixture was agitated periodically to enhance proper reaction between the solvent and the powder, and then poured into air-tight plastic container. The containers with the mixtures were then kept for 72hours (Oladunmoye, 2006). The mixtures were filtered with WhatMan No 1 filter paper. The filtrates were then separately concentrated using Rotary Evaporator to $10 \%$ of their original volumes at $37^{\circ} \mathrm{C}-40^{\circ} \mathrm{C}$. These were concentrated to complete dryness in water bath. The extracts were stored in a refrigerator from where aliquots were used for the phytochemical and antioxidant capacity assay (Oladunmoye, 2012).

Qualitative Phytochemical Analysis of Extracts

This was carried out according to the methods of Wadood et al.,(2013).

Quantitative Phytochemical Analysis of Extracts

This was carried using the methods of Chang et al.,(2002).

Determination of Total Phenol Content

Total phenols were determined using FolinCiocalteu reagent. Total phenol contents were expressed in terms of gallic acid equivalent ( $\mathrm{mg} / \mathrm{g}$ of dry mass), which is used as a reference compound (McDonald et al., 2001).

\section{Antioxidant Property of the Extract (Free Radical Scavenging Ability of the Extract)}

This was carried out according to Serpen et al., (2012) using inhibition of 1,1 diphenyl-2-picrylhydrazyl (DPPH) radicals expressed in trolox equivalent antioxidant capacity (TEAC) and Ferric reducing antioxidant power (FRAP) of extract expressed in gallic acid equivalents (GAE).

The reducing property of the extract was determined by assessing the ability of the extract to reduce ferric chloride $\left(\mathrm{FeCl}_{3}\right)$ solution as described by Pulido et al., (2000).

\section{Statistical Analysis}

All experiments were carried out in-replicates and reported as means with their standard error of mean (S.E.M) using SPSS version 20.0.

III. Results And Discussion

Table 1: Name and Part of Plants Tested

\begin{tabular}{|l|l|l|l|}
\hline Name of Plant & Common Name of Plant & Part Used & Family \\
\hline Phyllantus amarus & Gale-o- wind & Leaf & Phyllanthaceae \\
\hline $\begin{array}{l}\text { Vernonia } \\
\text { amygdalina }\end{array}$ & Bitter leaf & Leaf & Asteraceae \\
\hline Jatropha curcas & Physic nut & Leaf & Euphorbiaceae \\
\hline Carica papaya & Pawpaw & Leaf & Caricaceae \\
\hline
\end{tabular}


Table 2: Qualitative Phytochemical Properties of leaf Extracts

\begin{tabular}{|c|c|c|c|c|c|c|c|c|c|c|c|c|c|c|c|c|}
\hline \multirow[t]{2}{*}{$\begin{array}{l}\text { METABOLI } \\
\text { TES }\end{array}$} & & & & & & & & & & & & & & & & \\
\hline & 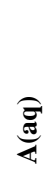 & 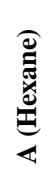 & 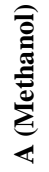 & 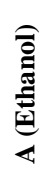 & $\underbrace{\overparen{\Xi}}_{\mathscr{\theta}}$ & 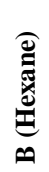 & 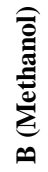 & 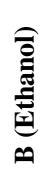 & $\underbrace{\text { త్ }}_{\text {త్ }}$ & 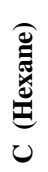 & 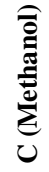 & 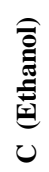 & $\underbrace{\text { త్ర }}_{0}$ & 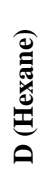 & 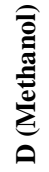 & 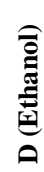 \\
\hline Alkaloids & ++ & ++ & ++ & ++ & + & + & + & + & + & + & + & + & + & + & + & + \\
\hline Tannins & + & + & + & + & ++ & ++ & ++ & ++ & ++ & ++ & ++ & ++ & + & + & + & + \\
\hline Phenol & + & + & + & + & ++ & ++ & ++ & ++ & ++ & ++ & ++ & ++ & + & + & + & + \\
\hline Saponin & + & + & + & + & ++ & ++ & ++ & ++ & + & + & + & + & ++ & ++ & ++ & ++ \\
\hline Terpenoids & - & - & - & - & + & + & + & + & - & + & - & + & ++ & ++ & ++ & ++ \\
\hline Steroids & - & - & - & - & + & + & + & + & - & - & - & - & + & + & + & + \\
\hline $\begin{array}{l}\text { Cardiac } \\
\text { glycosides }\end{array}$ & + & + & + & + & - & - & - & - & - & - & - & - & - & - & - & - \\
\hline Glycosides & - & - & - & - & + & + & + & + & - & - & - & - & - & - & - & - \\
\hline Flavonoid & ++ & ++ & ++ & ++ & + & + & + & + & + & + & + & + & ++ & ++ & ++ & ++ \\
\hline $\begin{array}{l}\text { Phlobatanni } \\
\text { n }\end{array}$ & - & - & - & - & + & - & - & - & - & - & - & - & - & - & - & - \\
\hline
\end{tabular}

KEYS: A-Vernonia amygdalina

B-Phyllanthus amarus

- Not detected

+Slightly present

\author{
C-Jatropha curcas \\ D-Carica papaya \\ ++ Moderately present \\ +++ Strongly present
}

Table 3: Quantitative Phytochemical Properties of Plant leaf

\begin{tabular}{|l|l|l|l|l|l|}
\hline Samples & Alkaloids (mg/g) & Phenols (mg/g) & Saponin (mg/g) & Tannins (mg/g) & Flavonoids (mg/g) \\
\hline A & $0.229 \pm 0.19$ & $0.567 \pm 0.14$ & $0.090 \pm 0.17$ & $0.349 \pm 0.21$ & $3.622 \pm 0.14$ \\
\hline B & $0.206 \pm 0.01$ & $0.917 \pm 0.12$ & $0.214 \pm 0.11$ & $0.593 \pm 0.18$ & $0.560 \pm 0.17$ \\
\hline C & $0.198 \pm 0.17$ & $0.636 \pm 0.21$ & $0.184 \pm 0.23$ & $0.424 \pm 0.20$ & $1.297 \pm 0.24$ \\
\hline D & $0.158 \pm 0.22$ & $0.203 \pm 0.20$ & $0.223 \pm 0.27$ & $0.126 \pm 0.17$ & $2.673 \pm 0.13$ \\
\hline
\end{tabular}

Table 4: Total Antioxidant Capacity of plant leaf

\begin{tabular}{|l|l|l|}
\hline SAMPLE & \% Inhibition of DPPH (mmol TEAC/100g of sample) & \%FRAP mgGAE/100g sample \\
\hline A & $6.764 \pm 0.23$ & $117.407 \pm 0.17$ \\
\hline B & $38.943 \pm 0.11$ & $165.076 \pm 0.24$ \\
\hline C & $18.162 \pm 0.24$ & $142.124 \pm 0.22$ \\
\hline D & $1.306 \pm 0.20$ & $63.624 \pm 0.14$ \\
\hline
\end{tabular}

KEYS:
A. Vernonia amygdalina
B. Phyllanthus amarus
C. Jatropha curcas
D. Carica papaya

\section{Discussion}

The results obtained from this study clearly show that the leaf extracts of the test plants contain some proportions of important phytochemicals which include alkaloids, tannins, saponins, flavonoids, phenols, steroids, glycosides, cardiac glycoside while phlobatanins was mostly absent (Table 2). The degree of extraction of this phytochemicals varies according to the polarity of the solvents, hence the quality and concentration of each chemical revealed in the different solvent (Table 3). It has been shown that these plants possess significant medicinal value which can be attributed to the presence of these chemical constituents in the extracts in varying quantities (Okiki et al., 2015).

Free radical scavengers have come to light of utmost importance in treating infections and diseases, hence the development of interest in it amongst researchers in the past years. Their wide range of activity in biological systems has shown their importance in alleviating the pathogenesis of certain diseases and deteriorative process of ageing (Vasthi and Devarajan, 2012). There are many reports that support the use of antioxidant supplementation in reducing the level of oxidative stress and in slowing or preventing the development of complications associated with diseases (Vasthi and Devarajan 2012). Numerous plant 
constituents have proven to show free radical scavenging or antioxidants activity which could be useful if harnessed properly (Vasthi and Devarajan, 2012). Free radicals are also involved in many degenerative disorders and cancer, while antioxidants due to their scavenging activity are useful in the management of those diseases (Koleva et al.,2002; Suresh et al., 2011).The potential of local medicinal plants in reducing such free radical suggests that many plants possess antioxidant activities that can be of significant therapeutic use (Kanatt et al.,2007).

Furthermore, total plant phenolics constitute one of the main groups of compounds acting as primary antioxidants or free radical scavengers(Cook and Samman, 1996), therefore it is important to determine the total amount of phenols in the selected plant extracts as this can correlate to the antioxidant activity and this study showed that the test plant extracts vary significantly in their percentage ferric reducing antioxidant potentials expressed in gallic acid equivalents(GAE) ranging from $63.624 \pm 0.14$ to $165.076 \pm 0.24 \mathrm{mg} / 100 \mathrm{~g}$ and all the sample extracts exhibited moderate to significant percentage inhibition of DPPH activity expressed in trolox equivalent (TAEC) ranging from $1.306 \pm 0.20$ to $6.764 \pm 0.23 \mathrm{mg} / 100 \mathrm{~g}$. P.amarus showed the highest free radical scavenging potential, followed by V. amygdalina, J.curcas and C. papaya showing the lowest scavenging power and inhibition percentage (Table 4). The level of phenol content in this plant may be reason for the difference in the radical scavenging effect, the phenols contain functional hydroxyl group that are said to be responsible for this scavenging effect due to its reduction-oxidation properties (Rice-Evans et al., 1997; Li et al., 2006).

Hence according to this study, the quantity of phenolic content in each plant extract is suggestive of the extent of its free radical scavenging activity as there is a significant correlation between the phenol content and the radical scavenging activities as the more the phenolic composition, the higher the antioxidant potentials of the plant extract that is, the reducing power of extracts expressed in gallic acid equivalents(GAE) and the percentage inhibition expressed in trolox equivalent (TAEC), this is in line with the reports of Yang et al. (2009) which says there is a direct correlation between total phenols and antioxidant capacity in numerous plants.

However, there is evidence that the radicals scavenging activity may not only be due to the phenolic content but with other various antioxidant compounds present in the plants (Khamsah et al., 2006).

In conclusion, this study showed the presence of significant phytochemicals in the test plants and the quantities available through solvent extraction exhibit that all the plants possess pharmacological active chemicals. The plants showed moderate to significant antioxidant activity as well as free radical scavenging potentials which may be explored for usage in the management and treatment of diseases, although the potentials of each plant may vary as each plant exhibits different antioxidant potentials as reflected in the values (Table 4).

However, more work needs to be done in order to ascertain which of these phyto-constituents has the greatest potency in exhibiting therapeutic or prophylactic value as well as further researches to determine the constituent responsible for the antioxidant activities of the plants because these medicinal plants, especially in Africa, may lead to alternative and effective approach in management and treatment of a number of existing and emerging diseases

\section{References.}

[1] Adeyemi, O.O., Okpo, S.O. and Ogunti, O.O. (2002). Analgesic and anti-inflamatory effects of the aqueous extract of leaves of Pesrsea Americana Mill (Lauracea). Fitoterapia, 2(73) 375-380.

[2] Akpanabiatu, M.I., Umoh, I.B., Udosen, E.O., Udoh, A.E. and Edet, E.E. (2005). Rat serum electrolytes, lipid profile and cardiovascular activity on Nauclea latifolia leaf extract administration. Indian J. Cli. Biochem. 20 (2) 29-34.

[3] Anderson, K. J., Teuber, S. S., Gobeille, A., Cremin, P., Waterhouse, A. L., \& Steinberg, F. M. (2001). Walnut polyphenol ics inhibit in vitro human plasma and LDL oxidation. Biochemical and molecular action of nutrients. J. Nutri., 131, 2837-2842.

[4] Chang,C., Yang, M., Wen, H and Cheru J. (2002). Estimation of total flavonoids content in propolis by two complementary colormetric methods. J. Food Drug Anala. 10: 178-82.

[5] Cook, N.C.; Samman, S. (1996) Flavonoids - Chemistry, metabolism, cardioprotective effects and dietary sources. J. Nutr. Biochem.7, 66-76.

[6] Deshpande, S.N., Kadam, D.G. (2013) Preliminary phytochemical analysis of some medicinal plants; DAV Int. J. Sci. 2(2).61-65.

[7] Gabriel, A., Agbor, D.K. \& Julius E.O. (2007).Medicinal plants can be good sources of antioxidants: case study in Cameroon. Pak. J. bio. sci. 10 (4) 537-544.

[8] Hadi, S., Bremner. B.(2001) Initial studies on alkaloids from Lombok medicinal plants molecules 6: 117-129.

[9] Khamsah, S. M., Akowah, G. and Zhari, I. (2006). Antioxidant activity and phenolic content of Orthosiphonstamineus benth from different geographical origin. J. of Sus. Sci. Man. 1: 14-20.

[10] Kanatt SR, Chander R, Sharma A (2007). Antioxidant potential of mint (Menthaspicata L.) in radiation- processed lamb meat. Food Chem. 100: 451-458.

[11] Koleva I.I, Van Beek T.A, Linseen J.P.H, de Groot A, Evstatieva L.N (2002). Screening of plant extracts for antioxidant activity: a comparative study on three testing methods. Phytochem. Anal. 13:817.

[12] Li, B. B., Smith, B. and Hossain, Md. M. (2006). Extraction of phenolics from citrus peels: I. Solvent extraction method. Separation and Purification Technology 48:182-188.

[13] McDonald S, Prenzler P.D, Autolovich M, Robards K. (2001). Phenolic content and antioxidant activity of olive extracts. Food Chem. 73: 7384

[14] Oladunmoye M. K. (2012) Antioxidant, free radical scavenging capacity and antimicrobial activities of Mirabilis jalapa J. Med. Plants Res. 6(15), pp. 2909-2913 
[15] Oladunmoye, M. K. (2006). Comparative evaluation of antimicrobial activities and phytochemical screening of two varieties of Acalyphawilkesiana. Trends in App. Sci. Res .1: 538-541.

[16] Okiki PA, Olatunji BP, Egbebi A, Asoso S, Ojo O (2015). A comparative study of Nutritional and phytochemical composition of Phyllanthus amarus leaf and seed. Am-Eur. J. Toxicol. Sci. 7(4):321-327.

[17] Pamplona-Roger,G. (1998).Encyclopedia of Medicinal Plants, Saeliz, Spain.

[18] Pulido, R.; Bravo, L.; Saura-Calixto, F. Antioxidant activity of dietary polyphenols as determined by a modified ferric reducing/antioxidant power assay. J. Agric. Food Chem. 2000, 48, 33963402

[19] Rice-Evans, C. A., Sampson, J., Bramley, P. M., \& Holloway, D. E. (1997). Why do we expect carotenoids to be antioxidants in vivo? Free Radical Res. 26, 381-398.

[20] Serpen, A., Capuano, E., Fogliano, V. and Gökmen, V. (2007). A new procedure to measure the antioxidant activity of insoluble food components. J. Agric. Food Chem., 55, 7676-7681.

[21] Suresh, V., Sruthi, V., Padmaja, B., Asha, V.V. (2011). In vitro anti-inflammatory and anti-cancer activities of CuscutareflexaRoxb. J. Ethnopharm. 134, 872-877.

[22] Vasthi Kennedy Evanjelene and Devarajan Natarajan 2012“In Vitro Antioxidant and Phytochemical Analysis of Acalyphaalnifolia Klein Ex Willd". J. Pharm. Bio. Sci. Vol, 1 PP 43-47

[23] Wadood, A., Ghufran, M., Jamal, S.B , Naeem, M., Khan, A., Ghaffar, R. Asnad(2013). Phytochemical analysis of medicinal plants occurring in local area of Mardan. Biochem anal biochem. 2:4.

[24] Yang, J., Liu, R. and Halim, L. (2009). Antioxidant and anti-proliferative activities of common edible nut seeds. Food Sci. Tech. 42: $1-8$ 